\title{
Parametric Studies on Detergent Using Low Cost Sorbent
}

\author{
Priti Shirbhate *, Dr. Mujahid Husain**, Prof. Joyti Mali*** \\ * PG Student of SSBT'S College of Engineering, Bambhori, Jalgaon. Maharashtra. \\ **HOD of Civil Department, SSBT'S College of Engineering, Bambhori \\ ***Prof. and Project Guide, SSBT'S College of Engineering, Bambhori.
}

\begin{abstract}
Water is a valued natural resource for the existence of all living organisms. Indian rivers are polluted due to the discharge of untreated sewage and industrial effluents. Management of the quality of this precious resource is, therefore, of special importance. In these study industrial effluents samples from the various detergent factories were collected and analyzed for physicochemical and bacteriological evaluation of pollution. The use and effectiveness of granular and powder activated carbon made from agricultural waste i.e. coconut husk and that coconut husk is a suitable adsorbent for such an effluent. Maximum adsorption capacity is a derived from Langmuir isotherm. A series of fixed bed experiments was carried out and the results were applied to a bed-depth/service time model for column adsorption. The validity of such a model is discussed. In the removal of organic matter in wastewater effluents from a industry waste water were investigated. The effect of process variables such as carbonization temperature, carbonization duration and activation temperature on the production and quality of activated carbon was studied as well as adsorption capacity was studied.
\end{abstract}

Keywords - Activation temperature, Adsorption, carbonization, Coconut husk as activated carbon, Detergent waste water sample.

\section{INTRODUCTION}

The water contamination by toxic metals through the discharge of industrial wastewaters is a worldwide environmental problem. Water is super abundant on the planet as a whole, but fresh potable water is not always available at the right time or the right place for human or ecosystem use. Water quality refers to the physical, chemical and biological characteristics of water.

Wastewater may be purely domestic or may contain some industrial wastewater as well. Residential waste water is a combination of excreta, flush water, and all types of wastewater generated from household. It is more commonly known as sewage and much diluted. There are two types of domestic sewage: black water or wastewater from toilet sand gray water, which is wastewater from all sources except toilets. Industrial wastewater comes from commercial activities (shops, restaurants, fast food shops, hospitals, etc.), industries (e.g., chemical industries, pharmaceutical companies, textile manufacturing, etc.), agriculture (e.g. Slurry), and so forth. Wastewaters from dyeing operations are characterized by color caused by both organic and inorganic compounds .The organic compounds are more problematic in industrial effluent than inorganic materials because, apart from the color, it imparts on the wastewater, biodegradation of organic material in the dye depleting the dissolved oxygen of the water thereby stressing aquatic microbes .Traditional wastewater treatment technologies have shown to be ineffective for handling detergent because of the chemical stability of these pollutants . There is no single or economically attractive method of treatment of Industries wastewater ,although notable achievements were made in the use of biotechnological approaches to solving the problem. In addition to biological treatment, many physical and chemical treatment methods have been employed for detergent removal from wastewaters such as coagulation, flocculation, filtration, oxidation or reduction, complex formation, or neutralization. New adsorption/oxidation, adsorption/reduction, and many combined processes were reviewed while radiation induced degradation process for treatment of wastewater. Solid sorbents have been employed in adsorption techniques to remove certain classes of chemical pollutants from waters; activated carbon is the most successfully used, but the high operating International Journal of Chemical Engineering costs and problems with regeneration of the spent activated carbon discourage its large-scale application. Therefore, a number of nonconventional sorbents have been tried for the treatment of wastewaters, in this class are various industrial wastes, agro waste, or natural materials available in large quantity at low cost and are classified as alternative sorbents for the removal of inorganic and organic pollutants from wastewaters . In this present study, the aim is to determine the efficacy of chemically modified and unmodified biological (portentous and cellulosic) waste sorbents in treatment of detergent wastewater; also the effect of particle sizes, carbonization (activation), and contact time will be established. 


\section{Materials And Methods \\ 2.1. Collection of Sorbents and Preparation. \\ Cellulosic waste sorbents (coconut-husk (coir)) were procured from a local market around Navi Mumbai. They were thoroughly washed with soap solution, sun dried for two days before drying in an oven at $105^{\circ} \mathrm{C}$ for 2 hours, and then ground. Ground material was carbonized at temperature of $80{ }^{\circ} \mathrm{C}$ for $30 \mathrm{mins}$, cooled and activated with $\mathrm{H} 2 \mathrm{SO} 4$, and further heated at a temperature of $500^{\circ} \mathrm{Cfor}$ complete carbonization. The carbonized materials were again pulverized. Materials were sieved into two particle sizes of $325 \mu \mathrm{m}$ and $625 \mu \mathrm{m}$ using mechanical sieve.}

\subsection{Column preparation.}

$2.5 \mathrm{~g}$ of each sorbent (both carbonized and uncarbonized and each particle size) were separately packed in glass adsorption column with inner diameter $2.2 \mathrm{~cm}$, bed height $3-18 \mathrm{~cm}$; the wastewater was eluted into it and allowed a contact time of 60 and 120 minutes. The wastewater was collected after 60 and 120 mins, respectively, and all the previous parameters were again determined to ascertain the Percentage absorption after each batch. The flow rate was varied between $25-75 \mathrm{ml} / \mathrm{min}$.

Adsorption isotherms are useful in providing information on the effectiveness of the adsorption system. However, the isotherms are obtained under equilibrium conditions. In most industrial treatment applications, the contact time is not sufficiently long for equilibrium to be achieved. In order to establish the suitability of coconut husk in removing detergent on a continuous basis, some flow studies using columns were conducted. For column operation, the husk is in constant contact with a fresh solution and hence equilibrium is unlikely to be attained. The usefulness of a column is related to the length of time before renewal or regeneration is necessary. For this purpose, the determination of breakthrough curve at different bed depths and flow rates is necessary.

\subsection{Wastewater Collection and Analysis.}

Detergent wastewater was collected from MIDC Taloja, Navi Mumbai. Physicochemical parameters of the wastewater were analyzed before and after contacting with the adsorbents for each contact time and particle size. Nitrate was determined according to American Public Health method, and chemical oxygen demand (COD) was determined by the dichromate method. Biological oxygen demand (BOD) and dissolved oxygen (DO) were determined electrochemically. The chloride content was determined by colorimetric method; while total suspended solid (TSS) and total dissolved solid (TDS) were determined by their respective standard methods. A standard $\mathrm{pH}$ meter was used to determine the $\mathrm{pH}$, and a digital conduct meter (consort $\mathrm{K} 120$, Belgium) was used to determine electrical conductivity (EC). Heavy metals ( $\mathrm{Pb}, \mathrm{Mn}, \mathrm{Ni}$, and $\mathrm{Cr}$ ) were determined at their respective wavelengths $(281.5,278,231$, and 358)nm after digestion using clean filtrates of the samples by means of atomic absorption spectrophotometer $205 \mathrm{~A}$.

\subsection{Analysis.}

Measurements commonly made include temperature, $\mathrm{pH}$, conductivity, Dissolved Oxygen (DO) and turbidity. Apart from the field observations other parameters- Alkalinity, Total solids, Dissolved and Suspended Solids, Total Hardness, Sulphate, Phosphate, Chloride, Fluoride, Nitrate, Chemical Oxygen Demand (COD), Biochemical Oxygen Demand (BOD).

The sample was collected from TALOJA MIDC, Navi Mumbai. Then these samples were distributed in various fractions $\&$ analyzed for various parameters before passing through a activated carbon bed. Then Different activated columns of coconut husk bed by above method were prepared \& the collected waste water sample was passed through it from the fixed bed for different contact time period. After that the sample is collected at the different time interval with different contact time \& subjected for analysis for different parameters like PH, conductivity, D.O, turbidity, hardness, sulphate, Phosphate chloride, etc. Now these parameters were compared to the parameters analyzed before passing through the bed. From this comparison the amount of the various content adsorbed by the activated carbon bed (coconut Husk) is observed.

\subsection{Adsorption Isotherms:}

Adsorption isotherms were obtained by passing the detergent water sample through activated carbon coconut husk. The results from adsorption studies at equilibrium can be used to determine the maximum of detergent adsorbed by the husk by using a modified Langmuir isotherm shown below.

$$
\text { (1) } \mathrm{Ce} / \mathrm{Ne}=1 /(\mathrm{N} * \mathrm{~b})+\mathrm{Ce} / \mathrm{N}^{*}
$$

Where $\mathrm{Ne}$ is the amount of detergent adsorbed per gram of husk at concentration Ce. Despite its lower adsorptive power, coconut husk, a cheap agricultural by product, could still be used to remove phosphate from wastewaters. 


\subsection{Activated carbon yield}

The activated carbon yield was calculated based on Eq. (2)

(2) Yield $(\%)=\mathrm{W}_{c} / \mathrm{W}_{\mathrm{o}} \times 100$

Where $\mathrm{W}_{\mathrm{c}}$ the dry weight $(\mathrm{g})$ of final activated carbon and $\mathrm{W}_{\mathrm{o}}$ is the dry weight $(\mathrm{g})$ of precursor.

\subsection{The composition of coconut husk}

Moisture $=15.0 \%$, Lignin $=43.0 \%, \mathrm{Ash}=8.26 \%$, Alkalinity of ash $\left(\right.$ as $\left.\mathrm{K}_{2} \mathrm{O}\right)=37.5 \%$

\subsection{Environmental hazards.}

- Water and air pollution amongst major environmental issues.

- Environmental issues need to be addressed in the immediate future in order to maintain ecological balance

- Growing dye industries, pharma industries cause major water pollution.

- In many areas, water is contaminated with toxic materials as well as heavy metals.

- To develop a new, economic and fast acting method to control water pollution is the need of the day.

\subsection{Physical Properties.}

- Activated carbon has the strongest physical adsorption forces or the highest volume of adsorbing porosity of any material known to man.

- Very high surface area $500-1500 \mathrm{~m} 2 / \mathrm{g}$.

- Highly porous structure - Consists of micro-pores and macro-pores

\section{Methdology}

The sample i.e. waste water which is highly contained detergent in it. It is collected from TALOJA MIDC CETP CO. SO. LTD, at Raigad District.

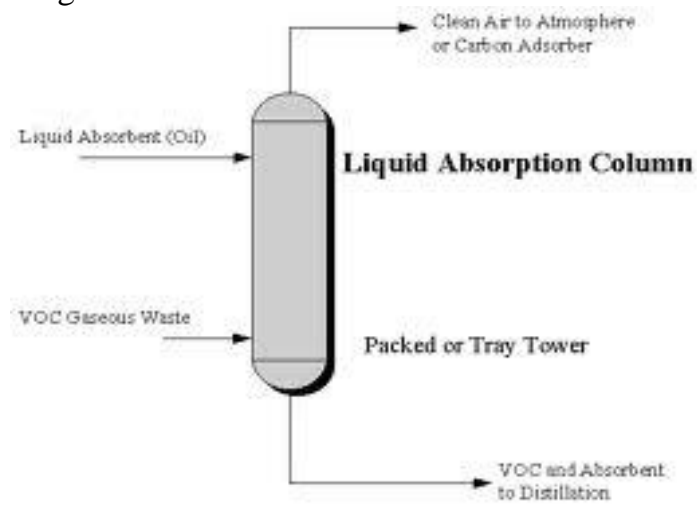

"Fig. column method by using coconut husk"

\subsection{Column Study}

Adsorption isotherms are useful in providing information on the effectiveness of the adsorption system. However, the isotherms are obtained under equilibrium conditions. In most industrial treatment applications, the contact time is not sufficiently long for equilibrium to be achieved. In order to establish the suitability of coconut husk in removing detergent on a continuous basis, some flow studies using columns were conducted. For column operation, the husk is in constant contact with a fresh solution and hence equilibrium is unlikely to be attained. The usefulness of a column is related to the length of time before renewal or regeneration is necessary. For this purpose, the determination of breakthrough curve at different bed depths and flow rates is necessary. PERTANIKA VOL. 13 NO.2, 1990

\subsection{Activated carbon characterization.}

The raw coconut husk was found to be high in volatile matter and moderate carbon content, indicating the suitability of coconut husk to be used as precursor for activated carbon preparation. After undergoing activation process, the volatile matter content decreased significantly whereas the fixed carbon content increased in activated sample. Similar trend was observed for the elemental analysis where the carbon content increased up to $73.8 \%$ for coconut husk activated carbon. This was due to the pyrolytic effect at high temperature where 
most of the organic substances have been degraded and discharged both as gas and liquid tars leaving a material with high carbon purity

The BET surface area, total pore volume and average pore diameter of the prepared activated carbon were found to be $370.75 \mathrm{~m} 2 / \mathrm{g}, 0.385 \mathrm{~cm} 3 / \mathrm{g}$ and $2.61 \mathrm{~nm}$, respectively. The average pore diameter of $2.61 \mathrm{~nm}$ indicates that the coconut husk activated carbon prepared was in the mesopores region. During the activation, $\mathrm{CO} 2$ gas molecules diffuse into the carbon structure thus increases the $\mathrm{CO} 2$-carbon reaction, thereby developing more pores on the sample. From the SEM micrograph, the raw coconut husk surface texture was undulating with very little pores as shown in Fig. 3a. After activation process, pores were developed with homogeneous distribution on the coconut husk activated carbon surface (Fig 3b).

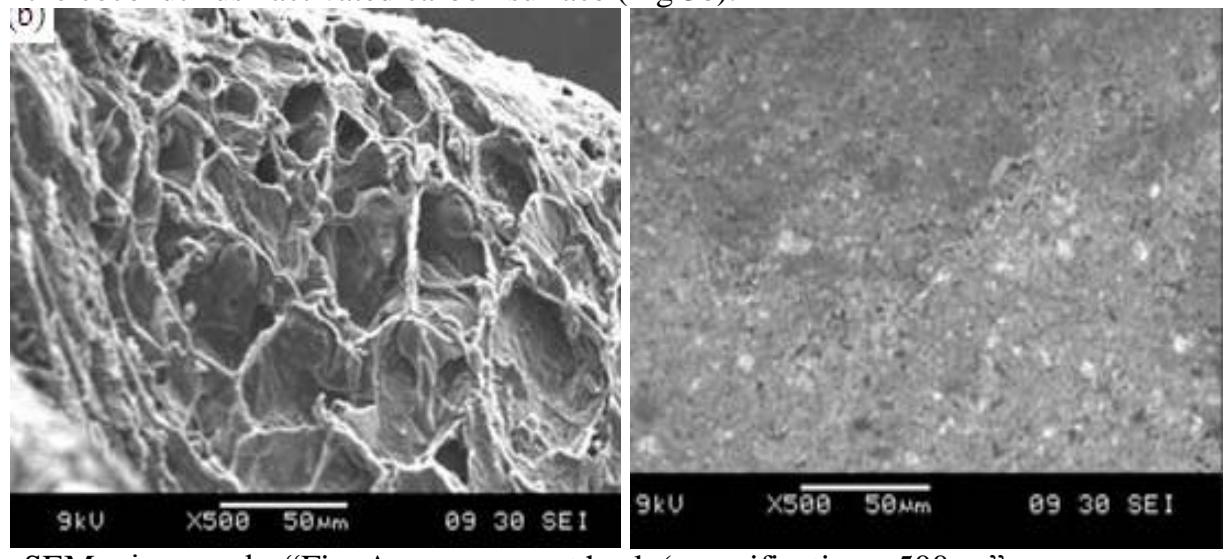

SEM micrographs "Fig. A. raw coconut husk (magnifications: $500 \mathrm{xs"}$

"Fig. B Coconut husk activated carbon (magnifications: 500 xs"

\subsection{Method of pore size distribution:}

The typical methods to measure the pore size distribution of power and materials are the gas adsorption and mercury porosimetry. The pore size distribution from the gas adsorption method is commonly analyzed from the nitrogen or Ar adsorption isotherm at their boiling temperature, and it is possible to evaluate the pore size from the molecular size to a few hundred $\mathrm{nm}$. The realistic largest detectable pore size is just over $100 \mathrm{~nm}$ due to the restriction from the pressure sensor accuracy and temperature stability of coolant. Mercury porosimetry calculates the pore size distribution by pressurizing mercury, which is non-wetting, and measure the corresponding intrusion amount. By this method, it is possible to detect the pore size from a few $\mathrm{nm}$ to $1000 \mu \mathrm{m}$ within a short period of time. For the pore size measurement below $10 \mathrm{~nm}$, it requires over $140 \mathrm{MPa}$ of pressure for the intrusion of mercury, so it is necessary to make sure that the material has the strength to withstand the pressure. Also, by this method, it evaluates the pore size of inkbottle neck (the smallest diameter of the pore) from the principle. The realistic measurement range is from a few $10 \mathrm{~nm}$.

Recently, there are bubble point method and gas permeation method to measure the through pore size of filters and separation membranes.

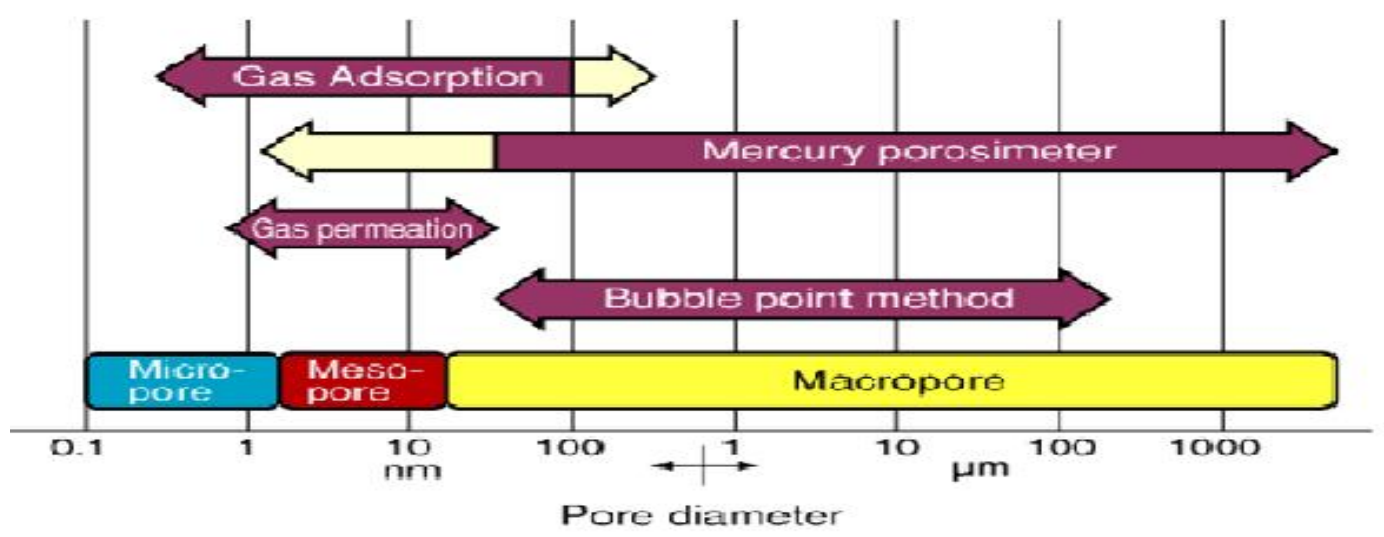

"Fig. Determination of pore size distribution" 


\section{Sampling And Field Work}

Measurements commonly made include temperature, $\mathrm{pH}$, conductivity, Dissolved Oxygen (DO) and turbidity. Apart from the field observations other parameters- Alkalinity, Total solids, Dissolved and Suspended Solids, Total Hardness, Sulphate, Phosphate, Chloride, Fluoride, Nitrate, Chemical Oxygen Demand (COD), Biochemical Oxygen Demand (BOD).

According to the united coconut Association of Philippines (UCAP), the average weight of coconut fruit is $0.4 \mathrm{Kg}$. It has been established that $30 \%$ of the husk can be obtained as commercial coir fiber.

\section{Conclusion}

Acentral composite design was conducted to study the effects of activated carbon preparation variables, which were the activation temperature, activation time and chemical impregnation ratio, activated carbon yield. Quadratic models were developed to correlate the preparation variables to the two responses. Through analysis of the response surfaces derived from the models, whereas activation temperature showed the most significant effect on activated carbon yield. Process optimization was carried out and the experimental values obtained and carbon yield were found to agree satisfactorily with the values predicted by the models. The optimal activated carbon was obtained using $300^{\circ} \mathrm{C}$ activation temperature, $2 \mathrm{~h}$ activation time and impregnation ratio, resulting in $20.16 \%$ of carbon yield and $191.73 \mathrm{mg} / \mathrm{g}$ uptake. From the SEM image obtained, large and well-developed pores were clearly found on the surface of the activated carbon. Various functional groups on the prepared activated carbon were determined from the FTIR results.

\section{Journal Papers:}

\section{References}

[1] International journal of scientific \& technology research volume 1, issue 8, September $2012 \quad$ ISSN 2277-861652 IJSTR@2012 www.ijstr.org A Study of Water Quality of Kaushalya River in the Submountaneous Shivalik Region Rhythm Aggarwal, Dr. Shakti Arora.

[2] International Journal of Applied Science and Technology Vol. 2 No. 1; January 2012 165, treatment of brewery wastewater effluent using activated carbon prepared from coconut shell.

[3] Ahalya N, Kanamadi RD and Ramachandra TV 2006, Biosorption of Iron (III) using the husk of Cicer arientinum. Indian Journal of Chemical Technology, 13, pp 122-127

\section{Chapters in Books:}

[4] .R.W. Gaikwad, Removal of Cd (II) from aqueous solution by activated charcoal derived from coconut shell, EJEAFChe. 3 (2004) 702-709.

[5] K. S. Low, C. K. Lee, The removal of cationic dyes using coconut husk as an adsorbent, Pertanika 13 (1990) $221-228$.

[6] K. O. Olayinka, B. I. Alo, T. Adu, Sorption of heavy metals from electroplating effluents by low cost adsorbents II: use of waste tea, coconut shell and coconut husk, J. Applied Sci. 7 (2007) 2307-2313.

\section{Theses:}

[7] Removal of dyes and heavy toxic metals with adsorption technique using low cost adsorbents.

[8] Removal of Bi (III) with adsorption technique using coconut shell activated carbon as a low cost adsorbent.

[9] Ahalya N, Ramachandra TV and Kanamadi RD, 2006. Removal of hexavalent chromium using coffee husk. Bioresource Technology (Communicated)

[10] http://en.wikipedia.org/wiki/Activated_carbon 